\title{
Hyperglycemic conditions inhibit C3-mediated immunologic control of Staphylococcus aureus
}

Pamela S Hair ${ }^{1}$, Charlene G Echague ${ }^{1}$, Reuben D Rohn ${ }^{1,2,3,4}$, Neel K Krishna ${ }^{1,2}$, Julius O Nyalwidhe $e^{4,5}$ and Kenji M Cunnion ${ }^{1,2,3,4^{*}}$

\begin{abstract}
Background: Diabetic patients are at increased risk for bacterial infections; these studies provide new insight into the role of the host defense complement system in controlling bacterial pathogens in hyperglycemic environments.

Methods: The interactions of complement C3 with bacteria in elevated glucose were assayed for complement activation to opsonic forms, phagocytosis and bacterial killing. C3 was analyzed in euglycemic and hyperglycemic conditions by mass spectrometry to measure glycation and structural differences.

Results: Elevated glucose inhibited S. aureus activation of C3 and deposition of C3b and iC3b on the bacterial surface. S. aureus-generated C5a and serum-mediated phagocytosis by neutrophils were both decreased in elevated glucose conditions. Interestingly, elevated glucose increased the binding of unactivated C3 to S. aureus, which was reversible on return to normal glucose concentrations. In a model of polymicrobial infection, S. aureus in elevated glucose conditions depleted C3 from serum resulting in decreased complement-mediated killing of $E$. coli. To investigate the effect of differing glucose concentration on C3 structure and glycation, purified C3 incubated with varying glucose concentrations was analyzed by mass spectrometry. Glycation was limited to the same three lysine residues in both euglycemic and hyperglycemic conditions over one hour, thus glycation could not account for observed changes between glucose conditions. However, surface labeling of C3 with sulfo-NHSbiotin showed significant changes in the surface availability of seven lysine residues in response to increasing glucose concentrations. These results suggest that the tertiary structure of $\mathrm{C} 3$ changes in response to hyperglycemic conditions leading to an altered interaction of C3 with bacterial pathogens.
\end{abstract}

Conclusions: These results demonstrate that hyperglycemic conditions inhibit C3-mediated complement effectors important in the immunological control of S. aureus. Mass spectrometric analysis reveals that the glycation state of C3 is the same regardless of glucose concentration over a one-hour time period. However, in conditions of elevated glucose C3 appears to undergo structural changes.

Keywords: Complement C3, Staphylococcus aureus, Hyperglycemia, Immune evasion, Polymicrobial infection

\section{Background}

It has long been recognized that bacterial infections are more common in diabetic patients, especially $S$. aureus diabetic foot infections [1-3], but also more invasive infections like S. aureus endocarditis [4-6]. Limb-threatening infections are frequently polymicrobial with enteric Gram-negative bacteria and S. aureus present

\footnotetext{
* Correspondence: cunniokm@evms.edu

'Department of Pediatrics, Eastern Virginia Medical School, 855 West Brambleton Avenue, Norfolk, VA, USA

Full list of author information is available at the end of the article
}

[7-9]. In 2004, diabetics underwent 71,000 nontraumatic limb amputations (American Diabetes Association). In acute settings, hyperglycemia has been associated with increased risk for bacteremia [10] and increased risk of death from S. aureus bacteremia [11]. Understanding how pathogenic bacteria interact with critical host defenses in diabetes is a necessary prerequisite for the development of future prevention and treatment strategies.

The human complement system is a major component of innate immunity and plays a vital role in the control

\section{Biomed Central}


of many bacterial pathogens [12] including S. aureus [13-15]. C3 is the central component of the complement system and its activation to $\mathrm{C} 3 \mathrm{~b}$ is critical for bacterial opsonization and subsequent phagocytosis, generation of the anaphylatoxin C5a [16], and terminal complement cascade activation leading to membrane attack complexes (MAC) that can lyse Gram-negative bacteria [17]. Normal C3 levels in human serum is typically about 1 $\mathrm{mg} / \mathrm{ml}[18]$.

The impact of hyperglycemia on the complement system remains unclear. Diabetic patients are reported to have elevated levels of circulating $\mathrm{C} 3$ and $\mathrm{C} 4$, yet decreased ability to fix complement by IgG [19], suggesting impaired classical pathway activation. In an animal model of diabetes using non-obese diabetic (NOD) mice, hyperglycemia resulted in chronic $S$. aureus hindpaw infection and decreased killing of $S$. aureus in a wholeblood assay [20]. However, the role of complement was difficult to assess because the mice were C5-deficient and the whole blood-killing assays used heparin, which inhibits complement activation [21]. C3 has been reported to be slowly susceptible to glycation with only $20 \%$ glycation after 48 hours in a hyperglycemic environment [22]. It has also been shown that glucose can bind the biochemically active (thioester) site of C3 resulting in decreased attachment to the surface of microbes [23]. For this to occur however, activation of $\mathrm{C} 3$ by the alternative pathway was necessary to expose the reactive thioester $[24,25]$. It has also been postulated that $S$. aureus may improve the survival and pathogenicity of other organisms in polymicrobial infections in diabetes [26].

To our knowledge, published data do not exist with regards to the concentrations of complement proteins or complement activity in diabetic wounds. Blister fluid generated by burn injury have C3 levels decreased approximately two-thirds compared with serum [27]. Additionally, diabetic microvascular disease diminishes blood flow [28], potentially limiting C3 delivery to diabetic extremities. It is unknown to what extent C3 might be generated locally by macrophages [29] in diabetic wounds. Very limited data suggest that glucose levels in diabetic foot ulcers are decreased $6 \%$ compared with arterial levels [30].

The experiments below investigate the functional interaction between complement $\mathrm{C} 3$ and pathogenic bacteria in elevated glucose, focusing on S. aureus. Additionally, we utilize mass spectrometry to analyze the glycation and tertiary structure of C3 in euglycemic and hyperglycemic environments. In summary, elevated glucose inhibits the normal activation of $\mathrm{C} 3$ on the surface of S. aureus. Hyperglycemic conditions do not rapidly alter glycation of $\mathrm{C} 3$, but does appear to alter the tertiary structure.

\section{Methods}

\section{Ethics Statement}

Human blood was obtained from healthy volunteers for generating serum used as a reagent in these studies. Eastern Virginia Medical School IRB approved this study protocol: 02-06-EX-0216. Written informed consent was provided by study participants.

\section{Bacteria and growth}

S. aureus strain Reynolds was grown in $2 \% \mathrm{NaCl}$ Columbia broth at $37^{\circ} \mathrm{C}$ to stationary-phase growth [31], unless otherwise noted. A sortase-deficient isogenic mutant [32] was tested against strain Newman. Clinical isolates were obtained as discarded de-identified isolates (EVMS IRB 06-04-WC-0040) - speciation by CLSI criteria [33]. Three isolates were tested for each species: $E$. coli, E. cloacae, K. pneumoniae, P. aeruginosa, and S. marcescens. PFGE analysis confirmed non-identical strains.

\section{Buffers serum and complement components}

PBS was supplemented with glucose (D-(+)-Dextrose D9434 Sigma). Glucose concentrations were tested in ranges consistent with euglycemia (3 - $6 \mathrm{mmol} / \mathrm{l})$ [34] and moderate hyperglycemia (10-17 mmol/l) [35]. Complement activation was stopped with EDTA-GVBS ${ }^{-}$ buffer (veronal-buffered saline [VBS] with $0.1 \%$ gelatin and 0.01 M EDTA) [31]. Normal human serum (NHS) was prepared from human blood and pooled, as previously described [31]. Purified C3, C3b, and iC3b were purchased (CompTech) and tested for purity and functionality [36].

\section{Incubation of S. aureus with C3 or serum in glucose}

Washed bacteria $\left(1 \times 10^{9}\right)$ were combined with purified C3 $(1 \mu \mathrm{g}), \mathrm{C} 3 \mathrm{~b}$, or NHS in $100 \mu \mathrm{L}$ of PBS/glucose and incubated for 1 hour at $37^{\circ} \mathrm{C}$, unless otherwise noted. NHS percentage and glucose concentrations used are shown in each figure. Washed bacteria were stripped of C3fragments using methylamine, as previously described [31]. These amounts of bacteria are consistent with those commonly found in established $S$. aureus infections [37].

\section{Assays for C3-fragments and C5a}

Bound C3 was quantitated by total C3 ELISA. Flatbottom Immunlon-2 plates were coated with goat antihuman C3 antibody (Complement Technology) at 76 $\mathrm{ug} / \mathrm{ml}$ in a carbonate buffer overnight at $4^{\circ} \mathrm{C}$. Plates were washed three times with PBST (PBS with $0.1 \%$ Tween-20) and blocked with 3\% BSA/PBST for 2 hours at room temperature. Next, plates were incubated with test samples or pure C3 for use as a standard curve for 1 hour diluted in block buffer. Plates were washed as 
stated above and incubated with a chicken anti-human C3 antibody at a 1:25000 dilution (Sigma) for 1 hour at room temperature. Finally, plates were washed again and incubated with a goat anti-chicken HRP antibody at 1:1000 for 1 hour at room temperature. Plates were developed with TMB Substrate Solution (Thermo Scientific) and stopped with $2.5 \mathrm{~N} \mathrm{H} 2 \mathrm{SO} 4$. C3-fragments analyzed by Western blot were probed with antibody that recognizes the peptide chains of $\mathrm{C} 3, \mathrm{C} 3 \mathrm{~b}$ and $\mathrm{iC} 3 \mathrm{~b}$, as previously described [38]. NHS in PBS/glucose was incubated with $1 \times 10^{9} \mathrm{~S}$. aureus for 1 hour at $37^{\circ} \mathrm{C}$, sedimented, and measured for C5a using a C5a ELISA kit (R\&D Systems). C3a dot-blot quantitation was performed by titrating pure C3a (Complement Technology) and samples onto PVDF. The membrane was blocked with 3\% BSA/TBS Tween, probed with rabbit anti-C3a antibody (Complement Technology), washed, incubated with horseradish peroxidase-labeled anti-rabbit antibody (Sigma), washed, and followed by ECL. Optical densitometry measurements of the dots provided grey scale values from which a standard curve was generated and samples were quantitated by linear regression.

\section{Phagocytosis}

Neutrophils were purified from human blood, as previously described [39]. An aliquot of $1 \times 10^{9} \mathrm{~S}$. aureus, log-phase, was incubated in 5\% NHS in PBS/glucose and incubated for $15 \mathrm{~min}$. at $37^{\circ} \mathrm{C}$. An aliquot of bacteria/serum suspension was incubated with neutrophils in HBSS (20:1, bacteria: neutrophil), decreasing the final concentration of glucose to $0.3 \mathrm{mmol} / \mathrm{l}$, and tumbled for $45 \mathrm{~min}$. at $37^{\circ} \mathrm{C}$. Samples were fixed by cytospin, stained with acridine orange, quenched with crystal violet, and analyzed as previously described [39].

\section{Serum complement-mediated killing}

$2 \%$ NHS/PBS supplemented with glucose was incubated with $10^{9} \mathrm{~S}$. aureus for 1 hour at $37^{\circ} \mathrm{C}$, then sedimented and the supernatant was sterile filtered. A serum-sensitive $E$. coli isolate was grown to log phase and washed. In a microtiter plate, $100 \mu \mathrm{l}$ of the $S$. aureus-treated supernatant containing $2 \%$ NHS was combined with $10^{4}$ E. coli and incubated for 3 hours at $37^{\circ} \mathrm{C}$. Control samples were processed identically, but without serum. Bacteria were quantitated by colony counting.

\section{Mass spectrometry analysis of C3}

Purified C3 $(0.4 \mathrm{mg} / \mathrm{ml})$ was incubated in PBS with concentrations of glucose $(0,3 \mathrm{mM}, 6 \mathrm{mM}, 10 \mathrm{mM}$, or 17 $\mathrm{mM}$ ) for 1 hour at $37^{\circ} \mathrm{C}$. The samples were then biotinylated using the EZ-Link Sulfo-NHS-Biotin kit (Pierce, Rockford, IL) at a molar ratio of 10 biotins per lysine residue of $\mathrm{C} 3$. Excess biotin was removed by spin column and samples were separated by SDS-PAGE. C3 gel bands were excised and digested with trypsin and the extracted peptides were analyzed by ESI-LC MS/MS in a LTQ linear ion trap (Thermo Fisher) mass spectrometer using data dependent acquisition and dynamic exclusion, similar as described previously [40]. Normalized peptide extracts were automatically loaded on a CapTrap column (TR1/25109/32 C18; Michrom Bioresources Inc) via an autosampler, followed by chromatographic separation under the following conditions: Solvent A (0.1\% formic acid, 0.005\% HFBA) and Solvent B (95\% acetonitrile in $0.1 \%$ formic acid, $0.005 \%$ HFBA). The tryptic digests were eluted at $500 \mathrm{nl} / \mathrm{min}$ with PicoFrit columns (75 $\mu \mathrm{m}$ inner diameter, $2 \mu \mathrm{M}$ tip opening, New Objective, Woburn, MA) slurry-packed in house with $10 \mathrm{~cm}$ of reverse phase $5 \mu \mathrm{m} 100$ Angstrom Magic C18 resin (Michrom Bioresources, Auburn, CA). The acquisition cycle consisted of a survey MS scan with a set mass range from $350 \mathrm{~m} / \mathrm{z}$ to $1800 \mathrm{~m} / \mathrm{z}$ at the highest resolving power, followed by 5 data-dependent MS/MS scans using collision dissociation fragmentation (CID) method assisted with helium gas. Dynamic exclusion was used with the following parameters: exclusion size 50 , repeat count 3 , repeat duration $120 \mathrm{~s}$, exclusion time $180 \mathrm{~s}$, exclusion window $\pm 0.8 \mathrm{Da}$. Target values were set at $5 \times 10^{5}$ and $10^{4}$ for the survey and Tandem MS scans, respectively, and the maximum ion accumulation times were set at $200 \mathrm{~ms}$ in both cases. Regular scans were used both for the precursor and tandem MS with no averaging. In total, $15 \mathrm{MS}$ runs were performed with extensive blanks between each sample to avoid carryover of peptides that could bias quantification. Peak lists were generated using XCalibur (version 2.1). Sequence analysis was performed with MASCOT (version 2.2.03) using SwissProt $2010 \times($ SwissProt 57.1) database with a human taxonomy filter enabled that contained 516, 603 sequences entries. The database searches were performed with fixed modification as carbamidomethyl $(\mathrm{C})$ and variable modifications as oxidation (M), deamidation (N, D) phosphorylation (STY) and biotin labeled (K). Enzyme specificity was selected to trypsin with 2 missed cleavage sites. The mass tolerance was set at 0.8 Da for both precursor ions and fragment ions. Threshold score for acceptance of individual spectra was set at 0.05 . All the MS/MS spectra were manually inspected to verify the validity of the database search results. False discovery rates were estimated to be $0.25 \%$ on the protein level by searching a decoy version of the SwissProt protein database.

Relative protein quantitation was achieved by comparing the number of MS/MS spectra for the same protein between the three MS/MS analyses for each sample. An increase in protein abundance is directly related to the number of proteolytic peptides. An increase in the number (or abundance) of peptides increases the number of 
MS/MS generated. There is a linear correlation between spectral counts and relative protein abundance $\left(\mathrm{R}^{2}=\right.$ 0.9997 ) over 2 orders of magnitude [41]. Quantitation via spectral counting shows strong correlation with isotopic label based approaches such as ${ }^{14} \mathrm{~N} /{ }^{15} \mathrm{~N}$ [42] and precursor peak area intensity measurements [43]. Spectral count based quantitation has been widely applied across a diverse set of media [44]. In the current analyses, biotinylation of lysine residues in C3 after exposure to increasing concentrations of glucose was determined by spectral counting as follows. The sulfoNHS-biotin derivative reacts with the epsilon amino group of lysine residues thereby increasing the mass of the modified lysine residues by $226 \mathrm{Da}$. Glycated lysines were identified by the increase in mass of $162 \mathrm{Da}$ due to the addition of a hexose molecule.

Scaffold (Proteome Software, Portland, Oregon, USA) was used to validate protein identifications derived from MS/MS sequencing results. Scaffold verifies peptide identifications assigned by Mascot using the X! Tandem database search program. Scaffold then probabilistically validates these peptide identifications using PeptideProphet and derives corresponding protein probabilities using ProteinProphet. The relative abundance of biotin modified lysine residues/peptides was obtained by spectral counting using Scaffold Q software. Scaffold normalizes these data by averaging the spectrum counts for all of the bio-samples and then multiplying the spectrum counts in each sample by the average divided by the individual sample's sum [45].

\section{Statistical analysis}

Means and standard errors were calculated from independent experiments (Microsoft Excel XP). Statistical comparisons were made using Student $t$ test (Instat GraphPad). Linear regression analyses (InStat GraphPad) were performed for spectral counts relative to glucose concentration.

\section{C3 structural models}

Three-dimensional drawings of C3 was generated using PyMOL software http://www.pymol.org based on the reported crystallographic structure of C3 [46].

\section{Results}

Glucose inhibition of C3-mediated opsonophagocytosis of S. aureus

In order to test whether hyperglycemic conditions altered C3 activation and binding of activated C3-fragments (C3b and $\mathrm{iC} 3 \mathrm{~b}$ ) on the $S$. aureus surface, we performed Western blot analysis of C3-fragments stripped from $S$. aureus incubated in serum in euglycemic, 3 $\mathrm{mmol} / \mathrm{l}$ dextrose, and hyperglycemic, $17 \mathrm{mmol} / \mathrm{l} \mathrm{dex}$ trose, conditions (Figure 1A). In each serum concentration tested, more C3 beta-chain was present for the $17 \mathrm{mmol} / \mathrm{l}$ glucose condition compared with the $3 \mathrm{mmol} / \mathrm{l}$ glucose condition, suggesting that more C3 was binding to the $S$. aureus surface in elevated glucose over 1 hour. However, for the $17 \mathrm{mmol} / \mathrm{l}$ condition most of the C3 alpha-chain appears to be intact (114 $\mathrm{kDa}$ ) [29] and uncleaved suggesting that most of the C3 binding $S$. aureus in elevated glucose is not being activated to $\mathrm{C} 3 \mathrm{~b}$. As expected, in normal glucose conditions ( $3 \mathrm{mmol} / \mathrm{l}$ glucose), C3 is activated efficiently with minimal or no intact $\mathrm{C} 3$ alpha-chain present, resulting in the $104 \mathrm{kDa} \alpha$ ' fragment (C3b) and the $42 \mathrm{kDa} \alpha^{\prime} 2$ (iC3b) bound to the $S$. aureus surface. We then performed optical densitometry on Western blots from multiple independent experiments in 10\% NHS in both glucose conditions (Figure 1B). C3 alpha-chain densitometry was normalized to the invariant beta-chain, as previously described [47]. In $3 \mathrm{mmol} / \mathrm{l}$ glucose only C3b (35\%) and iC3b (65\%) were bound to the $S$. aureus surface with no intact C3 identifiable. In $17 \mathrm{mmol} / \mathrm{l}$ intact C3 was most prevalent (59\%) compared with $\mathrm{C} 3 \mathrm{~b}(20 \%)$ and $\mathrm{iC} 3 \mathrm{~b}$ (21\%) $(\mathrm{P}=0.002)$. In order to further test whether C3 activation by $S$. aureus was altered in elevated glucose we measured C3a generation by dot-blot analysis for varying concentrations of serum (Figure 1C). C3a generation was increased in $3 \mathrm{mmol} / \mathrm{l}$ glucose compared with $17 \mathrm{mM}$ glucose by 2 -fold $(\mathrm{P}=0.01)$ in $10 \% \mathrm{NHS}$ and 3 -fold $(\mathrm{P}=0.01)$ in $2 \%$ NHS. In order to evaluate for the possibility of $\mathrm{C} 3(\mathrm{H} 2 \mathrm{O})$ being generated in hyperglycemic conditions, we tested whether C3 in 3 or 17 $\mathrm{mmol} / \mathrm{L}$ glucose would be cleaved by the presence of purified factors $\mathrm{H}$ and I. C3 remained intact in conditions that efficiently cleaved $\mathrm{C} 3 \mathrm{~b}$ to $\mathrm{iC} 3 \mathrm{~b}$ suggesting that hyperglycemia was not generating $\mathrm{C} 3(\mathrm{H} 2 \mathrm{O})$ (Figure 1D). These findings suggested that C3 activation on the $S$. aureus surface was inhibited in elevated glucose thereby limiting deposition of $\mathrm{C} 3 \mathrm{~b} / \mathrm{iC} 3 \mathrm{~b}$ opsonins.

Limited generation of $\mathrm{C} 3 \mathrm{~b}$ on the $S$. aureus surface would be expected to decrease the formation of C5-convertases and generation of the potent anaphylatoxin $\mathrm{C} 5 \mathrm{a}$ [29]. S. aureus was incubated in serum in PBS/glucose and C5a generation was measured by ELISA (Figure $1 \mathrm{E})$. In $17 \mathrm{mmol} / \mathrm{l}$ glucose, $\mathrm{C} 5 \mathrm{a}$ generation was decreased 5-fold ( $\mathrm{P}=0.04)$ in $1 \%$ NHS and decreased 2fold $(\mathrm{P}<0.01)$ in $5 \%$ NHS. This suggested that elevated glucose inhibited serum complement activation by $S$. aureus which decreased anaphylatoxin generation, likely resulting from decreased activation of $\mathrm{C} 3$ on the staphylococcal surface.

Decreased deposition of $\mathrm{C} 3 \mathrm{~b} / \mathrm{iC} 3 \mathrm{~b}$ on $S$. aureus and decreased generation of $\mathrm{C} 5 \mathrm{a}$ in the presence of elevated glucose suggested that phagocytosis would also be inhibited. Thus, S. aureus were incubated in 5\% NHS for 15 minutes in PBS/glucose. A sample of this bacteria/ 


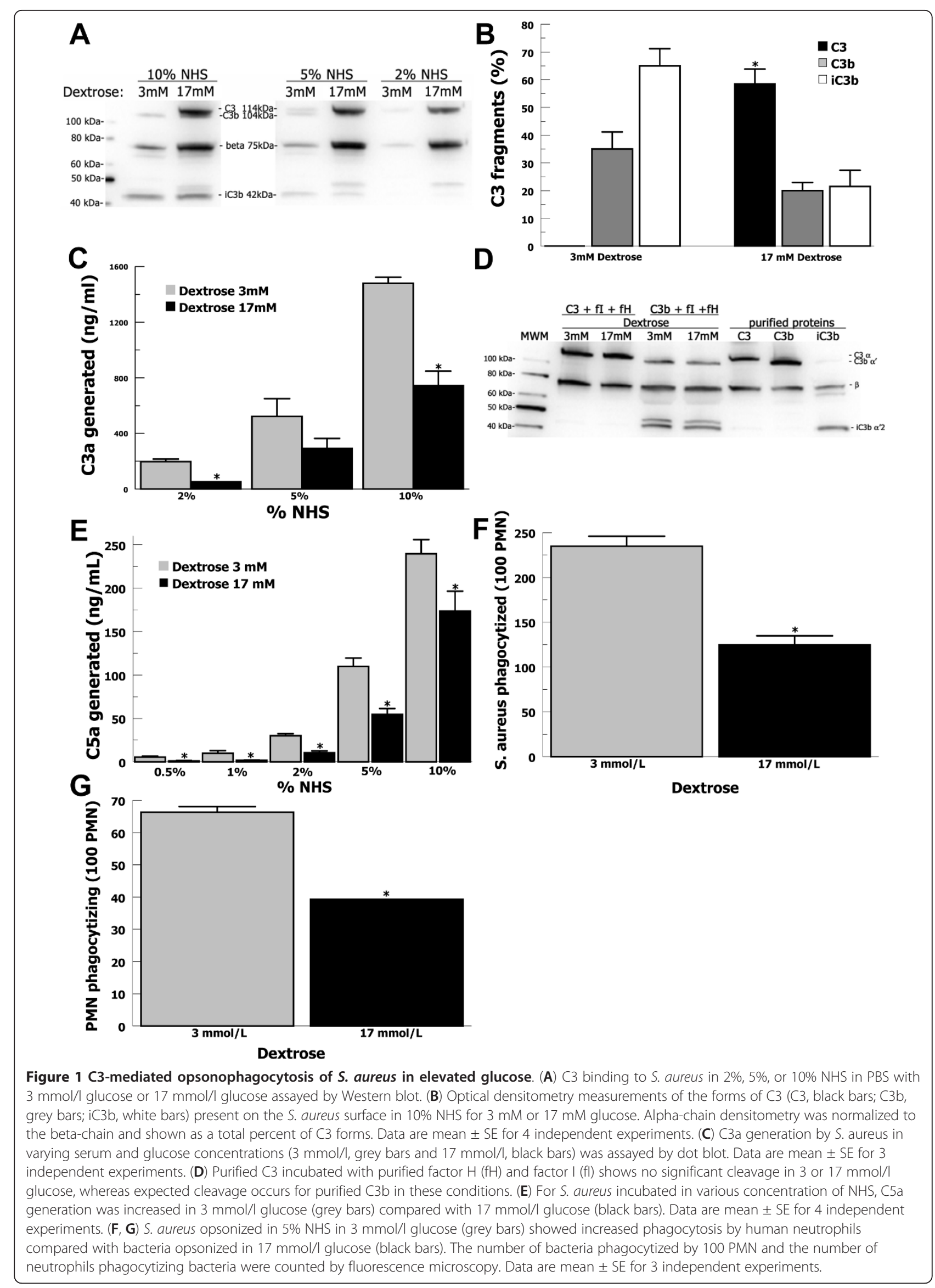


serum suspension was added to a suspension of purified neutrophils, diluting the concentration of glucose to 0.3 $\mathrm{mmol} / \mathrm{l}$, and incubated for 45 minutes. The number of $S$. aureus phagocytized after opsonization in $17 \mathrm{mmol} / \mathrm{l}$ glucose was decreased by 2 -fold $(\mathrm{P}<0.01)$ compared with $3 \mathrm{mmol} / \mathrm{l}$ glucose (Figure $1 \mathrm{~F}$ ) and the number of neutrophils phagocytizing bacteria was likewise decreased $(\mathrm{P}<0.01)$ in $17 \mathrm{mmol} / \mathrm{l}$ glucose (Figure $1 \mathrm{G}$ ). The concentration of glucose was diluted upon addition of bacteria to neutrophils to minimize glucose effects on neutrophil function. It is possible, however, that decreasing the glucose concentration could have increased complement activation during incubation with neutrophils resulting in diminished differences in phagocytosis efficiency. Nonetheless, these results suggest that elevated glucose inhibited complement-mediated opsonophagocytosis of S. aureus.

\section{Glucose concentration affects C3 binding to $S$. aureus without C3-convertase formation}

Initial Western blot analysis suggested that intact C3, without activation to $\mathrm{C} 3 \mathrm{~b}$, was binding to $\mathrm{S}$. aureus in elevated glucose conditions. In order to evaluate whether C3 binding could be replicated in the absence of other complement components, thus preventing convertase formation, we measured purified C3 binding to S. aureus. Bacteria were incubated for 1 hour in PBS/ glucose with purified C3 $(10 \mu \mathrm{g} / \mathrm{ml})$. C3 was stripped from washed bacteria and measured by ELISA (Figure 2A). In elevated glucose (17 mmol/l), C3 binding to $S$. aureus increased 6fold $(\mathrm{P}<0.01)$ compared with 3 $\mathrm{mmol} / \mathrm{l}$ glucose. C3 binding rapidly increased above 5 $\mathrm{mmol} / \mathrm{l}$ and reached saturation at $13-17 \mathrm{mmol} / \mathrm{l}$ (Figure 2B). Similar binding studies were performed with purified C3 and S. aureus in $\mathrm{GVBS}^{++}$and VBS buffers with similar results (data not shown). In order to evaluate serum C3 binding, but still prevent complement activation, bacteria were incubated with $0.5 \%$ NHS in EDTA-GVBS- - buffer supplemented with glucose (Figure $2 \mathrm{C}$ ). In the presence of elevated glucose (17 $\mathrm{mmol} / \mathrm{l})$, serum $\mathrm{C} 3$ binding increased 12 -fold $(\mathrm{P}=$ $0.049)$ compared with $6 \mathrm{mmol} / \mathrm{l}$ glucose. In order to test the contribution of anti-staphylococcal antibodies, we depleted these antibodies from serum under complement preserving conditions, as previously described [38]. The binding of intact C3 to S. aureus in hyperglycemic conditions was the same for specific antibody-depleted serum compared with NHS (data not shown). Overall, greatly increased C3 binding to $S$. aureus is found in elevated glucose concentrations similar to what would be found in moderate hyperglycemia (10-17 mmol/l) [35] as compared to euglycemia (3-6 mmol/l).

In order to exclude the possibility of spontaneous non-convertase-dependent $\mathrm{C} 3$ activation, we tested the binding of purified C3b to S. aureus (Figure 2D). Purified C3b is no longer capable of activation and cannot form covalent bonds. Bound C3b increased 14-fold for $17 \mathrm{mmol} / \mathrm{l}$ glucose compared with $3 \mathrm{mmol} / \mathrm{l}$ glucose $(\mathrm{P}=0.025)$. Western blot analysis confirmed minimal $\mathrm{C} 3$ binding in $3 \mathrm{mmol} / \mathrm{l}$ glucose and that intact $\mathrm{C} 3$ bound in $17 \mathrm{mmol} / \mathrm{l}$ glucose (Figure $2 \mathrm{E}$ ).

In order to evaluate whether glucose-mediated C3 binding to $S$. aureus is caused by the high osmolarity environment, we tested multiple sugars at the same osmolarities. S. aureus was incubated with purified C3 and galactose, sucrose, and raffinose at $3 \mathrm{mmol} / \mathrm{l}$ and 17 $\mathrm{mmol} / \mathrm{l}$, but $\mathrm{C} 3$ binding remained unchanged (Figure $2 \mathrm{~F})$, suggesting a mechanism other than osmolarity.

In order to evaluate the rapidity of glucose-mediated C3 binding to $S$. aureus, we performed time-course experiments. We also evaluated different phases of growth as this affects the surface expression for some $S$. aureus proteins [48]. S. aureus in stationary or midlogarithmic phase was incubated with purified C3 in PBS at elevated glucose levels $(17 \mathrm{mmol} / \mathrm{l})$ for increasing lengths of time (Figure 2G) and measured for C3 binding. C3 initially bound more slowly to stationary phase S. aureus compared with mid-logarithmic phase bacteria, but by 60 minutes the same amount of C3 was bound.

Because C3 appears to be binding S. aureus in elevated glucose without activation and formation of covalent bonds, we wanted to assess whether glucosemediated C3 binding to $S$. aureus would be reversed in a euglycemic environment. Purified C3 was allowed to bind to $S$. aureus in $17 \mathrm{mmol} / \mathrm{l}$ glucose, washed in PBS/ glucose $(3 \mathrm{mmol} / \mathrm{l})$, and then incubated in $\mathrm{PBS} /$ glucose (3 mmol/l) (Figure 2H). C3 bound to S. aureus decreased during washing in $3 \mathrm{mmol} / \mathrm{l}$ glucose and after 5 minutes the amount of bound $\mathrm{C} 3$ decreased a further 3 -fold ( $P=0.005)$. This suggested that glucose-mediated $\mathrm{C} 3$ binding to $S$. aureus is readily reversible upon return to euglycemic conditions.

\section{C3 binding to clinical S. aureus and Gram-negative isolates}

In order to evaluate whether glucose-meditated C3 binding to $S$. aureus is a general property of clinical $S$. aureus strains, we tested 8 clinical isolates (Figure 3A). All isolates were recovered from patients with invasive $S$. aureus disease; four isolates were methicillin-resistant (MRSA). Isolates were non-identical by pulse-field gel electrophoresis. For each isolate, elevated glucose concentration increased $\mathrm{C} 3$ binding significantly $(\mathrm{P} \leq 0.05)$. On average, $17 \mathrm{mmol} / \mathrm{l}$ glucose increased $\mathrm{C} 3$ binding 6 -fold ( $\mathrm{P}=0.001)$, suggesting that glucose-mediated $\mathrm{C} 3$ binding to $S$. aureus is a general property of clinical isolates. 

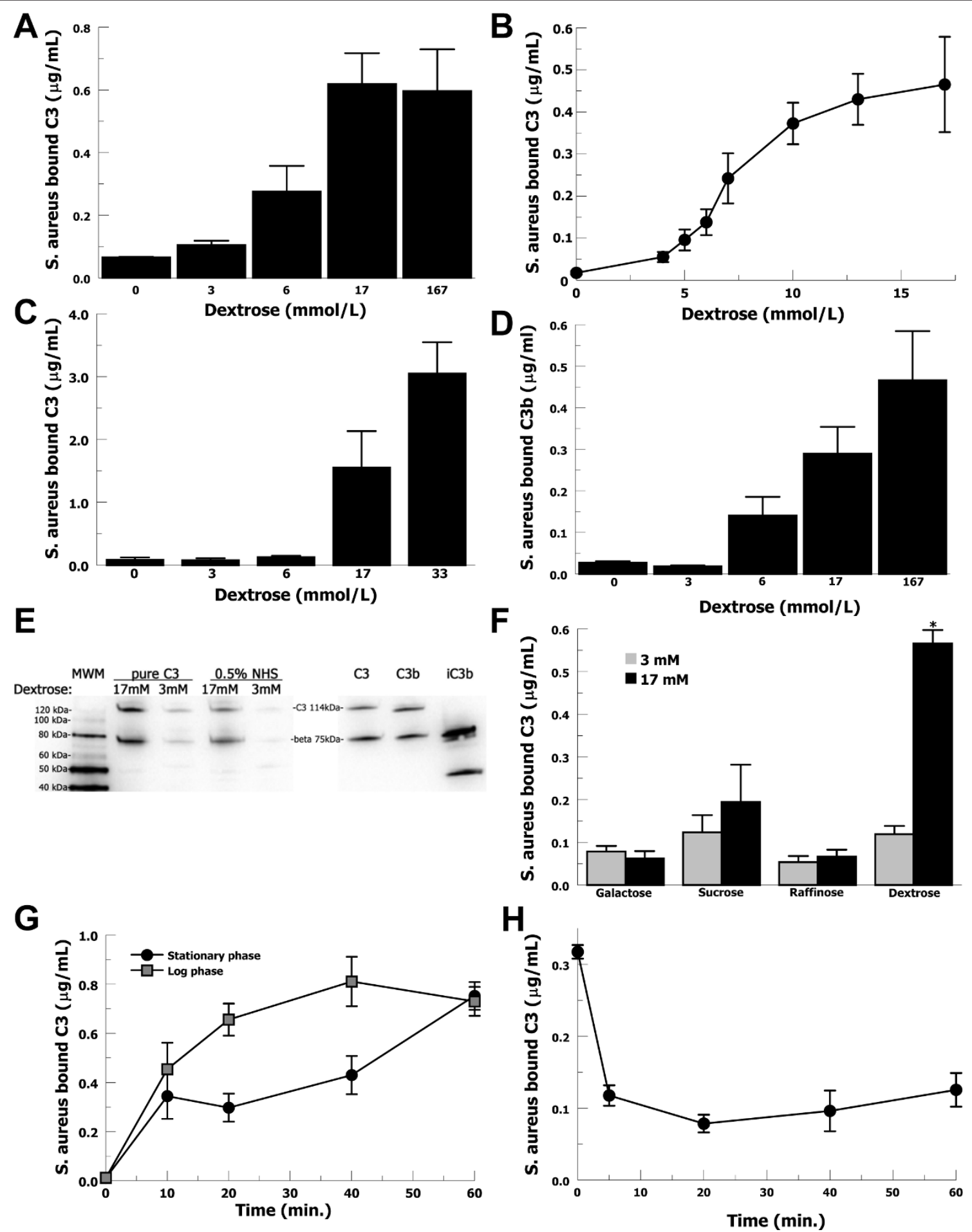

Figure 2 Purified and serum C3 binding to S. aureus in varying glucose concentrations. (A, B) Purified C3 (10 $\mu \mathrm{g} / \mathrm{ml}$ ) binding to S. aureus in PBS increases at elevated levels of glucose. Data are mean \pm SE for 4 independent experiments. (C) C3 binding to S. aureus incubated in $0.5 \%$ NHS in EDTA-GVBS - buffer, to prevent complement activation, increases at elevated glucose concentrations. Data are mean \pm SE for 4 independent experiments. (D) Purified C3b binding to S. aureus in PBS increased at elevated levels of glucose. Purified C3b is incapable of activation. Data are mean \pm SE for 4 independent experiments. (E) C3 bound to S. aureus incubated with purified C3 or $0.5 \%$ NHS in PBS was increased for $17 \mathrm{mmol} / \mathrm{l}$ glucose compared with $3 \mathrm{mmol} / \mathrm{l}$. Purified standards for C3 [alpha (114 kDa) and beta (75 kDa) chain and iC3b products $\alpha 2^{\prime}$ (42 kDa)] were included on the gel. (F) Purified C3 binding to S. aureus in PBS did not increase in $17 \mathrm{mmol} / \mathrm{l}$ (black bars) compared to 3 mmol/l (gray bars) for galactose, sucrose, or raffinose. Data are mean \pm SE for 4 independent experiments. (G) Purified C3 binding to stationary phase (black circles) or log phase (grey squares) S. aureus in elevated glucose $(17 \mathrm{mmol} / \mathrm{l})$ increased over time. Data are mean \pm SE for 3 independent experiments. (H) S. aureus bound by $\mathrm{C} 3$ in elevated glucose $(17 \mathrm{mmol} / \mathrm{l})$ and then incubated in $3 \mathrm{mmol} / \mathrm{l}$ glucose shows a rapid decrease for residual C3 bound to the bacteria. Data are mean \pm SE for 3 independent experiments. 


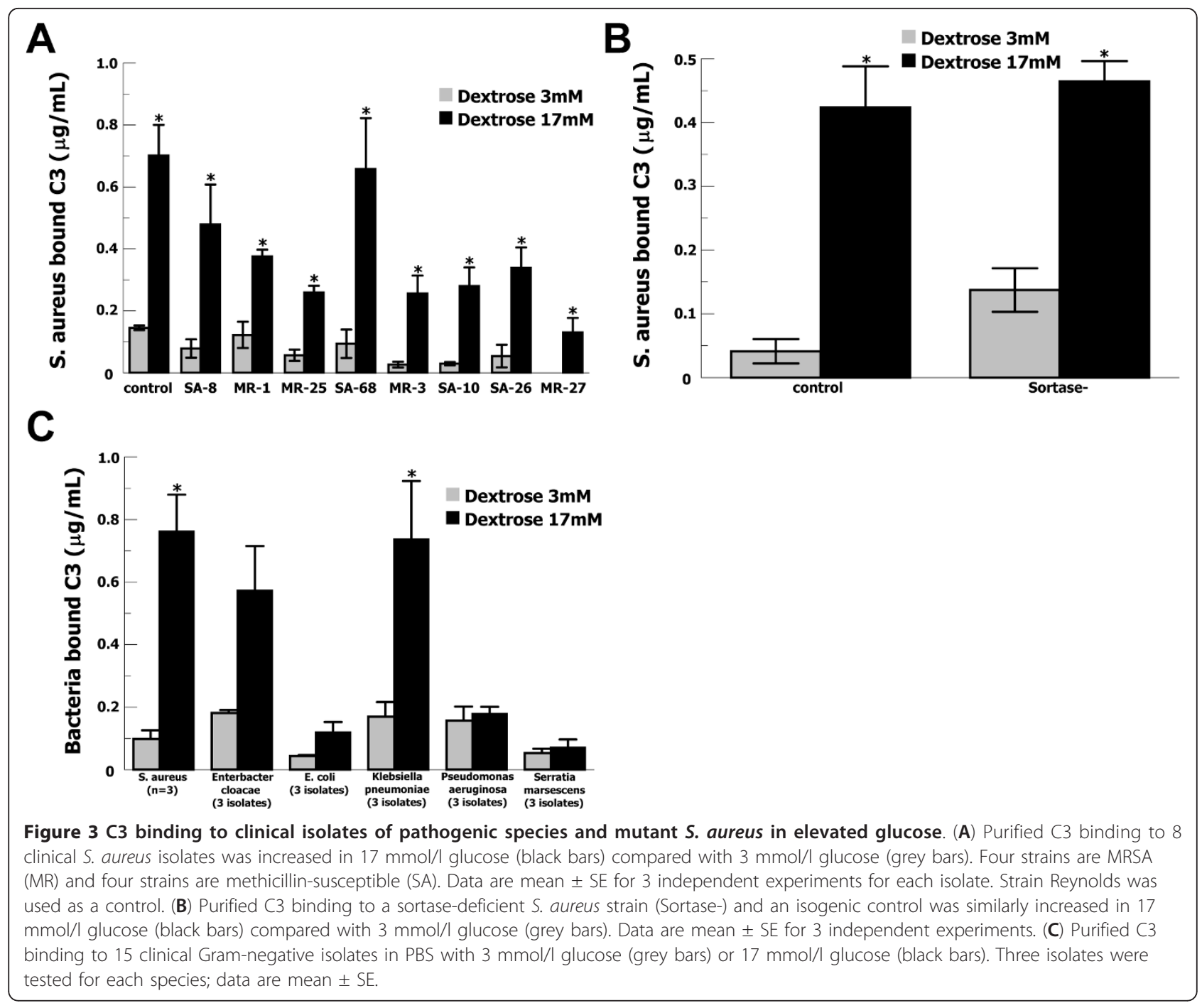

We speculated whether glucose-mediated C3 binding to $S$. aureus could be mediated by LPXTG-motif anchored cell-wall proteins. Therefore, we tested a sortase-deficient $S$. aureus strain [32] and its isogenic parent strain, Newman (Figure 3B). C3 binding in $17 \mathrm{mmol} / \mathrm{l}$ glucose was the same for both the parental strain and the sortase-deficient strain, suggesting that LPXTG-motif cell-wall proteins do not mediate this phenomenon.

In order to evaluate whether glucose-mediated $\mathrm{C} 3$ binding occurred for other bacterial species, we tested 15 Gram-negative clinical isolates (Figure 3C). Three isolates were tested for each of five species. Pulse-field gel electrophoresis testing demonstrated that strains were non-identical. Significantly increased C3 binding in $17 \mathrm{mmol} / \mathrm{l}$ glucose was found for $K$. pneumoniae $(\mathrm{P}=$ 0.04), but not $P$. aeruginosa, or $S$. marcescens. E. cloacae $(\mathrm{P}=0.07)$ and $E$. coli $(\mathrm{P}=0.07)$ strains suggested a trend towards significance. These results show that glucose-mediated C3 binding to bacteria also occurs for at least one Gram-negative species, but is not a generalized property for all bacterial species.

\section{C3 depletion from the local environment and complement killing of E. coli}

In light of the dramatic increases in C3 binding to $S$. aureus, we speculated that $S$. aureus in high glucose concentrations might deplete C3 from the local environment. C3-depletion could potentially play an important role in diabetic wound infections where C3 would likely be present in limited quantities. S. aureus was incubated with purified C3 $(10 \mu \mathrm{g} / \mathrm{mL})$ as above, sedimented, and supernatants measured for residual C3 by ELISA (Figure $4 \mathrm{~A})$. In conditions of elevated glucose $(17 \mathrm{mmol} / \mathrm{l})$, residual $\mathrm{C} 3$ concentrations decreased 10 -fold $(\mathrm{P}<0.01)$ compared with $3 \mathrm{mmol} / \mathrm{l}$ glucose. Using identical conditions, but without $S$. aureus, no differences in residual 
C3 concentration were found between any glucose concentrations (Figure 4B), showing that the C3 was not being lost by precipitation or binding to the wall of the reaction tube.
We then assayed whether C3 would be depleted from serum incubated with $S$. aureus in elevated glucose (Figure 4C). In 10\% serum, residual C3 decreased 2-fold $(\mathrm{P}=0.05)$ for $17 \mathrm{mmol} / \mathrm{l}$ glucose compared with 3

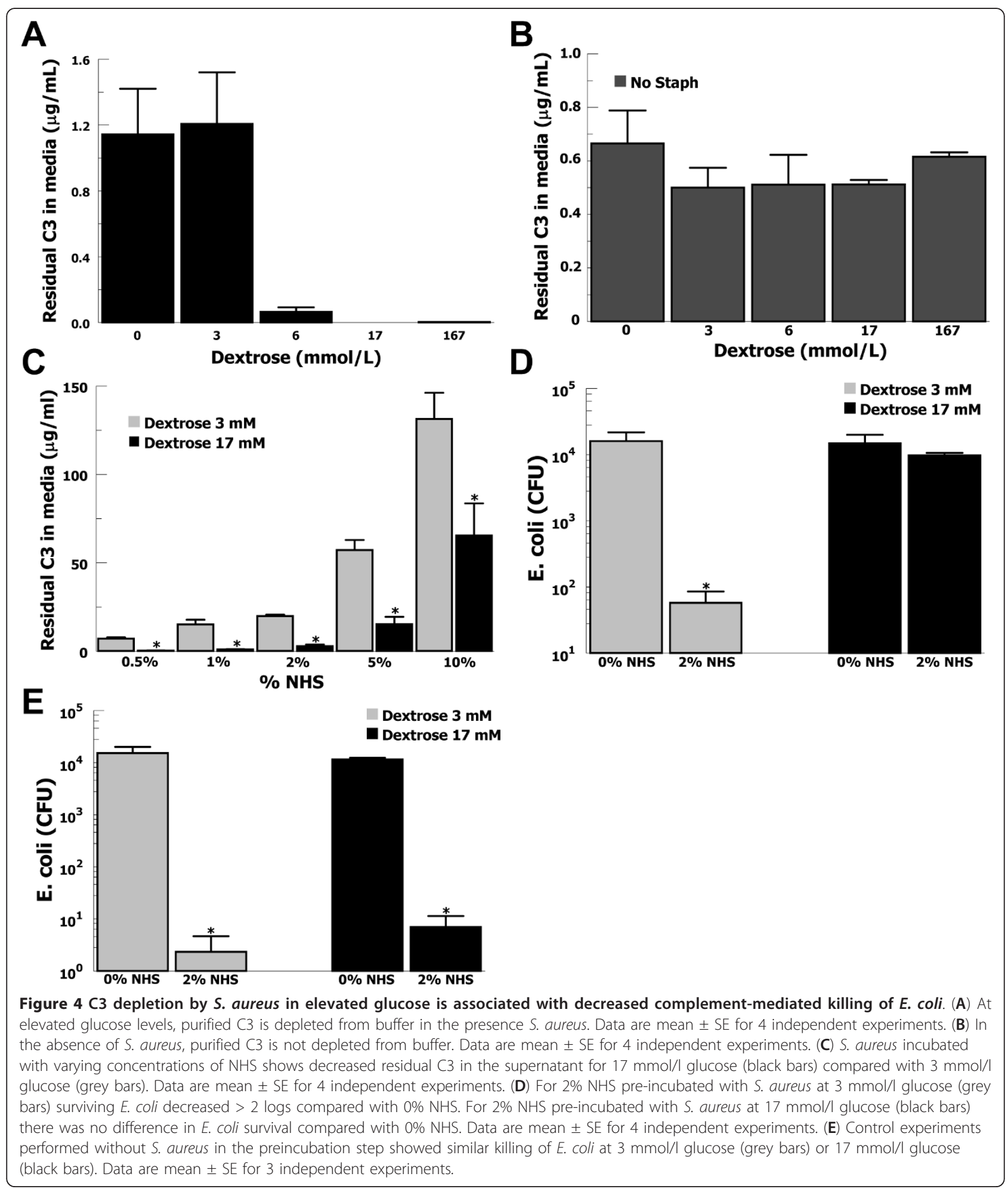


$\mathrm{mmol} / \mathrm{l}$ glucose. These results suggest that $S$. aureus may deplete $\mathrm{C} 3$ in local environments where $\mathrm{C} 3$ is present in limiting concentrations and glucose concentration is elevated, such as in diabetic wounds.

Given that C3 can be depleted from the local environment by $S$. aureus in elevated glucose, we speculated that Gram-negative bacteria susceptible to complementmediated lysis could incur a survival advantage in polymicrobial infections. Such an effect could greatly worsen the disease process in limb-threatening diabetic wound infections in which $S$. aureus and Gram-negative bacteria are commonly present [8]. S. aureus was incubated in PBS/glucose $\pm 2 \%$ serum for 1 hour and then removed from the solution. The serum solutions were then incubated with a serum-sensitive strain of E. coli for three hours and plated for colony counting (Figure $4 \mathrm{D})$. In $3 \mathrm{mmol} / \mathrm{l}$ glucose, the number of surviving $E$. coli in $2 \%$ NHS was decreased $>200$-fold $(\mathrm{P}=0.03)$ compared with no serum, typical of complementmediated lysis. However, in $17 \mathrm{mmol} / \mathrm{l}$ glucose, there was no difference in the numbers of surviving $E$. coli between $2 \%$ NHS and the no serum control. These results suggest that glucose-mediated depletion of C3 by $S$. aureus can inhibit complement-mediated lysis of Gram-negative bacteria improving their survival.

In order to test whether elevated glucose might prevent complement-mediated lysis of the E. coli, we repeated the previous experiments excluding $S$. aureus from the pre-incubation step (Figure 4E). This resulted in similar levels of complement-mediated killing of E. coli in 17 or $3 \mathrm{mmol} / \mathrm{l}$ glucose, suggesting that elevated glucose did not inhibit complement-mediated killing of E. coli.

\section{Mass spectrometry analysis of C3 glycation and structure in elevated glucose}

In order to evaluate whether the observed changes in C3 interaction with bacteria could potentially result from elevated glucose altering the C3 molecule, we used mass spectrometry-based techniques to evaluate the glycation and tertiary structure of C3. Purified C3 was incubated in either $0,3,6,10$, or $17 \mathrm{mmol} / \mathrm{l}$ glucose for 1 hour in PBS buffer and then modified by surface biotinylation. Each of these conditions was repeated in three independent experiments. After removal of excess biotin, the C3 molecules were digested to peptides and analyzed by ESI-LC-MS/MS. Typical peptide map coverage for each experiment was excellent at $\geq 61 \%$ yielding a cumulative peptide coverage of $88 \%$ (Figure $5 \mathrm{~A}$ ). Glycation analysis was performed for $\mathrm{C} 3$ for each glucose concentration, yet regardless of the glucose concentration tested (3 $17 \mathrm{mmol} / \mathrm{l}$ ) lysines K241/K242, K396, and K405/K406 were consistently glycated. Resolution was not sufficient to differentiate between glycation of K241 and K242 or
K405 and K406. Glycation of a lysine prevents subsequent biotinylation. A representative spectrum for the peptide sequence FLYGKKVEGTAFVIFGIQDGEQR containing K241/K242 is shown in Figure 5B. The glycated lysines all reside in the $\mathrm{C} 3$ beta chain and are shown superimposed on a structural model of C3 [46] (Figure 5C). These assays show that $\mathrm{C} 3$ is readily glycated at these lysine positions, even in normal glucose concentrations, and that over this time frame increasing concentrations of glucose do not alter the glycation pattern. This suggests that glycation is not responsible for changes in $\mathrm{C} 3$ interactions in hyperglycemia.

In order to evaluate whether changes in glucose concentration could alter the tertiary structure of C3, we performed surface modification using sulfo-NHS-biotin. Lysines on the surface of the molecule are more easily modified with biotin, whereas internal lysines are less available for modification. Thus, any alterations in the tertiary structure of the molecule would result in changing the availability of specific lysine residues for biotinylation. For the 15 samples tested in this analysis, 41 lysines were identifiable in every sample. Biotinylation increases the peptide mass by 226 Da which is detected by MS and the specific modified residue is identified by MS/MS. A representative spectrum for the fragmentation and annotation for the $\mathrm{C} 3$ peptide sequence AHEAKIR is shown in Figure 6A. The total sequence coverage achieved in the MS analysis to identify the peptides and modified lysine residues was $88 \%$. Most of the peptides that were not identified in the analyses have $\mathrm{m} / \mathrm{z}$ that fall out of the range of the MS instrument used. Spectral count analysis was performed to quantitate the frequency of biotinylation for each of the 41 lysine residues (Figure 6B). Spectral count analysis allows for the flexibility of molecules in physiological conditions in contrast to crystallized molecules which are static. Sixteen lysines were infrequently labeled with $\leq 5$ spectral counts total over 15 samples. These lysine residues were highly resistant to biotinylation for all conditions suggesting that they are not available for surface modification. Interestingly, seven lysine residues showed a statistically significant change in biotinylation relative to changing glucose concentration, as shown in Table 1. Increasing glucose concentration correlated with increasing biotinylation for K405/406, K534, K839, and K857, but decreasing biotinylation for K82, K1414, and K1578. The differentially labeled lysines in the domains of $\mathrm{C} 3$ [46] are shown in Figure 6C. The positions of the changing lysines are shown in threedimensional models in Figure 6D. These results strongly suggest that the tertiary structure of $\mathrm{C} 3$ changes as glucose concentration changes and may contribute to altering the interaction of $\mathrm{C} 3$ with bacteria in hyperglycemic conditions. 


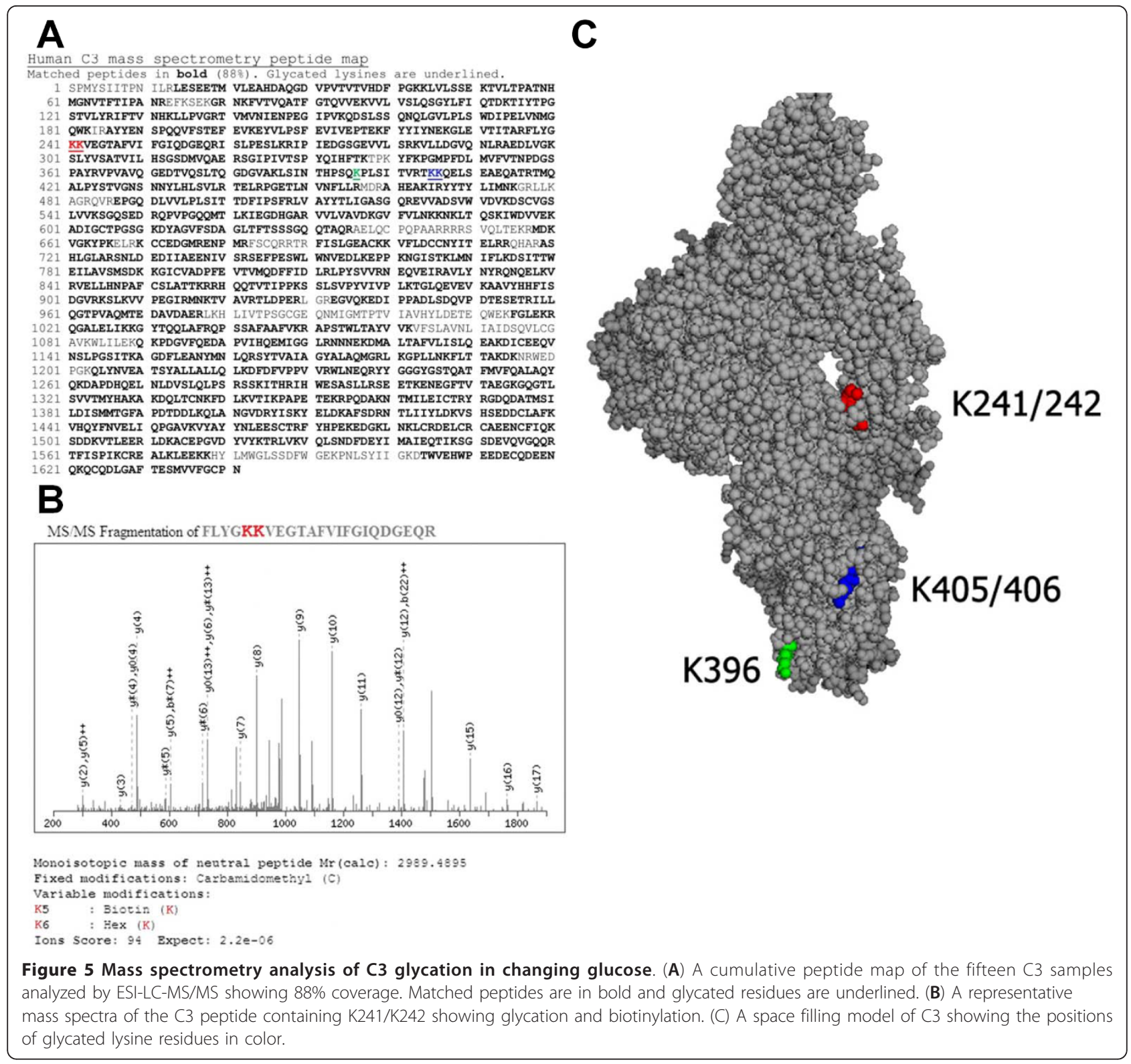

In order to more closely examine potential changes in the structure of C3 near the activating cleavage site Arg 726 - Ser 727, we analyzed the mass spectrometry data using threshold criteria to determine whether biotinylation of each lysine between regions MG6 $\beta$ and MG6 $\alpha$ was detected for each sample. This approach was used due to the limited spectral count data available for the lysines in this region. Biotinylation was detected for seven lysines in this region, three of which suggested changes in labeling between euglycemic and hyperglycemic conditions (Table 2 suggesting structural changes are likely occurring near the activating cleavage site, which may contribute to decreased C3 activation by pathogenic bacteria in hyperglycemic conditions.,). Two of these lysines (K585/586 and K611) were in MG6 $\beta$ and one (K757) was in MG6 $\alpha$

We had circular dichroism performed by Alliance Protein Laboratories (Camarillo, CA). Only very slight differences were noted in the CD patterns for the two conditions (data not shown). This is likely due to the relative insensitivity of $C D$ to detect subtle changes in the tertiary structure of large multi-domain molecules. Two prior publications show that harsh denaturing conditions are required to induce conformational changes in C3 that are detectable by CD $[49,50]$. Another publication suggests circular dichroism is relatively insensitive 


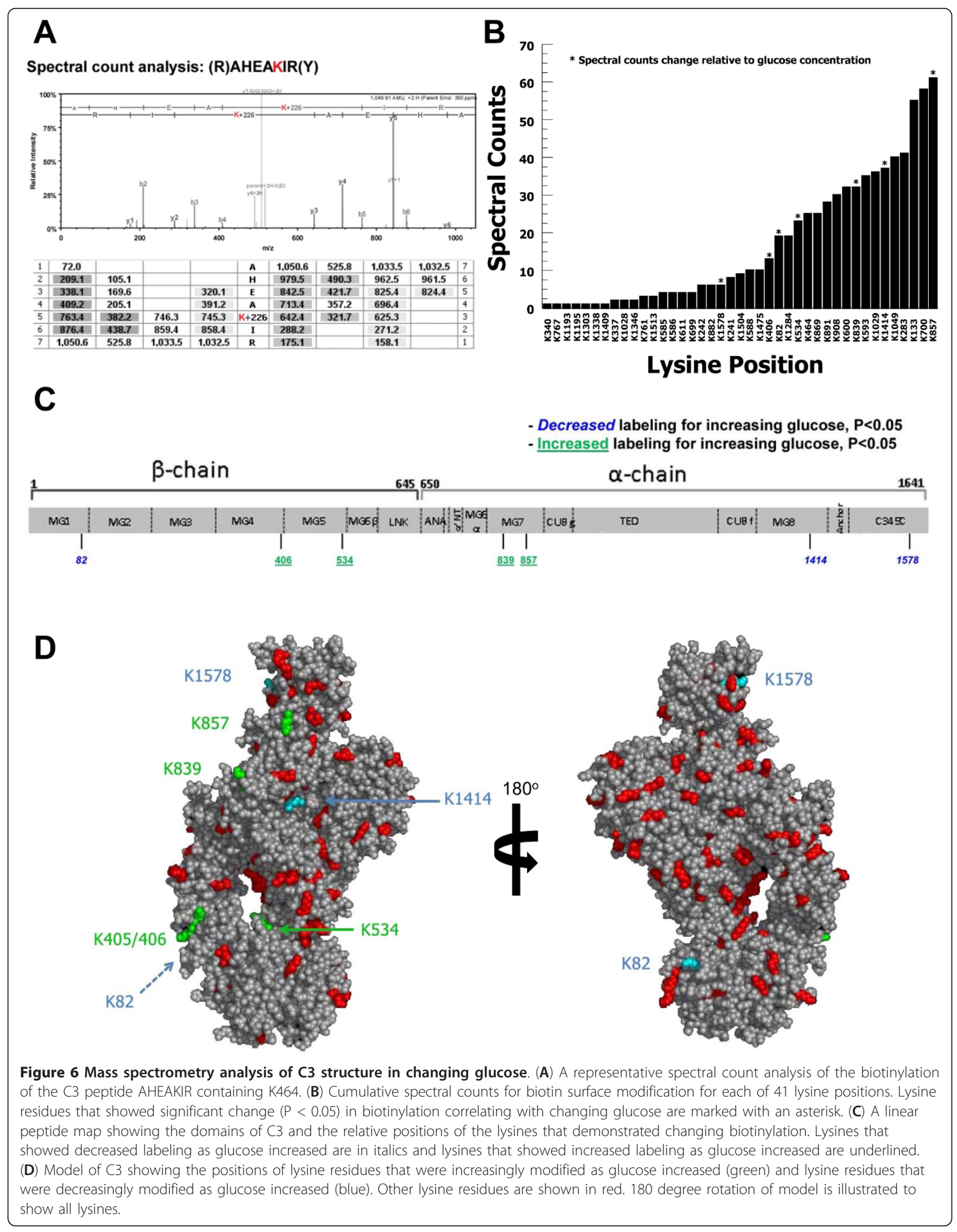


Table 1 Lysine residue spectral counts by dextrose concentration

\begin{tabular}{llllllll}
\hline \multicolumn{7}{c}{ Dextrose } \\
\hline Lysine & $\mathbf{0} \mathbf{~ m M}$ & $\mathbf{3} \mathbf{~ m M}$ & $\mathbf{6} \mathbf{~ m M}$ & $\mathbf{1 0} \mathbf{~ m M}$ & $\mathbf{1 7} \mathbf{~ m M}$ & Total & $\mathbf{P}$ \\
\hline K82 & 6 & 5 & 4 & 2 & 2 & 19 & 0.0264 \\
\hline K405/406 & 2 & 2 & 2 & 3 & 4 & 13 & 0.0164 \\
\hline K534 & 2 & 1 & 5 & 6 & 9 & 23 & 0.0242 \\
\hline K839 & 5 & 6 & 6 & 7 & 8 & 32 & 0.0011 \\
\hline K857 & 9 & 12 & 12 & 13 & 15 & 61 & 0.0110 \\
\hline K1414 & 9 & 8 & 8 & 6 & 6 & 37 & 0.0286 \\
\hline K1578 & 2 & 2 & 1 & 1 & 0 & 6 & 0.0163 \\
\hline
\end{tabular}

in detecting structural changes in large multi-domain molecules [51]. C3 is both large and complex with 1,641 residues and 13 domains [46].

\section{Discussion}

Decreased C3 activation by $S$. aureus, as measured by C3a generation, and decreased deposition of C3b and $\mathrm{iC} 3 \mathrm{~b}$ on the bacterial surface in elevated glucose strongly suggest that, at least in complement limited environments, hyperglycemic environments inhibit efficient C3-mediated opsonization of $S$. aureus. As expected, diminished deposition of $\mathrm{C} 3 \mathrm{~b} / \mathrm{iC} 3 \mathrm{~b}$ resulted in decreased phagocytosis by neutrophils and decreased $\mathrm{C} 3 \mathrm{~b}$ resulted in decreased C5a generation. Since the normal functioning of neutrophils is already impaired by elevated glucose $[52,53]$, it is likely that inefficient opsonization further retards phagocytosis. Thus, hyperglycemic conditions inhibit efficient complement-mediated opsonophagocytosis and generation of anaphylatoxin, likely contributing to diabetic immunocompromise manifested by frequent infections that are difficult to control.

It is interesting to note that use of continuous insulin infusion in the intensive care setting in order to rapidly correct hyperglycemia has been associated with

Table 2 Number of experiments for which lysine labeling was detected between C3 regions MG6 $\beta$ and MG6 $\alpha$

\begin{tabular}{llll}
\hline Lysine & $\begin{array}{l}\text { C3 } \\
\text { region }\end{array}$ & $\begin{array}{l}\mathbf{3} \mathbf{~ m M} \text { and } \mathbf{6} \mathbf{~ m M} \\
\text { glucose }\end{array}$ & $\begin{array}{l}\mathbf{1 0} \mathbf{~ m M} \text { and } \mathbf{1 7} \mathbf{~ m M} \\
\text { glucose }\end{array}$ \\
\hline K585/ & MG6 $\beta$ & 3 & 0 \\
586 & & & 5 \\
\hline K588 & MG6 $\beta$ & 4 & 6 \\
\hline K593 & MG6 $\beta$ & 5 & 5 \\
\hline K600 & MG6 $\beta$ & 6 & 2 \\
\hline K611 & MG6 $\beta$ & 0 & 5 \\
\hline K700 & ANA & 6 & 3 \\
\hline K757 & MG6 $\alpha$ & 0 & \\
\hline
\end{tabular}

improved survival [54], which may be due in part to the elevated risk of bacteremia in hyperglycemia [55]. We show that the binding of unactivated C3 is rapidly reversed upon return to euglycemic conditions suggesting that the abnormal interaction of $\mathrm{C} 3$ and bacteria can be reversed upon correction of hyperglycemia. We speculate that normalization of the interaction of $\mathrm{C} 3$ with bacteria by rapidly reversing hyperglycemia in critical care settings, where risks of invasive infection are elevated, may contribute to the improved survival.

Another important infectious complication for diabetics are polymicrobial limb-threatening infections that commonly involve $S$. aureus and Gram-negative bacteria [7]. Gram-negative bacteria, unlike Gram-positive bacteria, are often susceptible to complement-mediated killing via membrane attack complex formation and lysis. Given the limited levels of complement proteins likely to be present in diabetic wounds, we speculated that $S$. aureus might be able to further deplete $\mathrm{C} 3$ in such an environment and confer a survival advantage to Gramnegative organisms. These studies showed that $E$. coli killing by complement-mediated lysis was eliminated by the pre-incubation of serum with S. aureus in $17 \mathrm{mmol} /$ 1 glucose. This suggests that glucose-mediated C3 adsorption to $S$. aureus and depletion from the local environment can dramatically improve survival of Gram-negative bacteria from complement-mediated lysis and may contribute to the pathogenesis of limb-threatening polymicrobial infections.

Prior studies using biochemical methods have suggested that glycation of $\mathrm{C} 3$ in high concentrations of glucose is a very slow process [22], which is inconsistent with the rapid functional effects found in these studies. These new mass spectrometry data show that three lysine sites are glycated by 1 hour, but that the glycation results were the same regardless of euglycemic or hyperglycemic conditions. This is novel data delineating the sites where C3 is rapidly glycated, K241/K242, K396, and K405/K406. Since hyperglycemic conditions do not change the glycation compared with euglycemic conditions over short time frames, glycation is unlikely to account for the rapid ( $<1$ hour) changes in interaction with bacteria in elevated glucose. Prior studies have also suggested that upon activation by the alternative pathway, glucose can bind the critical thioester site of C3 [24]; however, our studies suggest that very limited amounts of C3 is activated on the S. aureus surface in the presence of elevated glucose. None of the lysines glycated in our assays reside within the thioester-containing domain (residues 963 - 1268) [46], suggesting that this was not an important mechanism over short time intervals.

We speculated that hyperglycemic conditions must either alter the C3 molecule or a component or 
components of S. aureus. Since glycation of C3 did not change in elevated glucose compared with euglycemic conditions, we tested whether increasing glucose concentration could change the conformation of $\mathrm{C} 3$. We assayed for this possibility by using mass spectrometrybased surface modification analysis of lysine biotinylation. Employing spectral count analysis provided quantitative measurement about how frequently a given lysine site was biotinylated. Of 41 lysines analyzed, over onethird were highly resistant to surface modification for all glucose conditions, suggesting that they occupy internalized or protected positions within the $\mathrm{C} 3$ molecule. Seven lysines were shown to undergo significant changes in surface modification relative to increasing glucose concentration, suggesting that these regions of the $\mathrm{C} 3$ molecule are becoming more or less surface exposed as glucose changes. The changing availability for surface modification suggests that the tertiary structure of $\mathrm{C} 3$ is changing in response to changing glucose concentration. The positions of the lysines with changing modification are distributed over the molecule suggesting that multiple areas of the molecule are undergoing structural alteration. These structural changes likely contribute to the altered interaction of C3 with bacteria in hyperglycemic environments. A recent study showed that high glucose inhibited the lectin pathway by inhibiting oligosaccharide recognition, but classical and alternative complement pathway activation were not inhibited in Weislab ELISA-style complement activation assays [56]. We confirmed in $\mathrm{CH} 50$ and AP50 assays that serum complement-mediated hemolysis was not altered by elevated glucose (data not shown). This suggests that changes in the structure of $\mathrm{C} 3$ likely contribute to the dramatically altered interaction with pathogenic bacteria, but are not so great as to globally cripple the ability of the molecule to function. Together with the rapid reversibility of functional effects upon return to euglycemic conditions suggests that the structural alterations are likely to result from non-covalent changes. It also remains undetermined whether hyperglycemic environments may alter the surface of pathogenic bacteria, as has been shown for yeast [57], contributing to the altered interaction with $\mathrm{C} 3$.

\section{Conclusions}

The principal finding of our study is that in conditions of elevated glucose, activation of complement C3 to functionally active forms $(\mathrm{C} 3 \mathrm{~b} / \mathrm{iC} 3 \mathrm{~b})$ on the $S$. aureus surface was inhibited. Curiously, elevated glucose caused the reversible binding of unactivated C3 to S. aureus. The limited activation of $\mathrm{C} 3$ on the $S$. aureus surface in elevated glucose was associated with decreased C5a generation and decreased phagocytosis. Mass spectrometric analysis demonstrated that the glycation of C3 was the same for euglycemic and hyperglycemic conditions over brief time periods and thus, could not account for the rapid changes in function. Mass spectrometry-based surface labeling experiments suggested that the tertiary structure of C3 was altered in the presence of increasing glucose. Thus, hyperglycemic conditions dramatically alter the interaction of $\mathrm{C} 3$ and pathogenic bacteria in surprising ways that provide new insight into hyperglycemia-mediated immunocompromise contributing to bacterial infections in diabetic patients.

\section{Acknowledgements}

This work was funded in part by American Diabetes Association Innovation Award 7-11-IN-03. The structural models of C3 showing the modified lysines were kindly drawn by Dr. Piet Gros, Universiteit Utrecht, Utrecht,

Netherlands. The sortase-deficient S. aureus strain was kindly provided by Dr. Timothy Foster, Trinity College, The University of Dublin, Dublin, Ireland. Pulse-field gel electrophoresis was kindly performed by Dr. E. Stephen Buescher, Eastern Virginia Medical School, Norfolk, VA. Access to the mass spectrometers of the George L. Wright, Jr., Center for Biomedical Proteomics was kindly provided by Dr. O. John Semmes. Circular dichroism was generously performed by Dr. Tsutomu Arakawa, Alliance Protein Laboratories, Camarillo, CA.

\section{Author details}

${ }^{1}$ Department of Pediatrics, Eastern Virginia Medical School, 855 West Brambleton Avenue, Norfolk, VA, USA. ²Children's Specialty Group, 601 Children's Lane, Norfolk, VA, USA. ${ }^{3}$ The Children's Hospital of The King's Daughters, 601 Children's Lane, Norfolk, Norfolk, VA 23501-1980, USA. ${ }^{4}$ Department of Microbiology and Molecular Cell Biology, Eastern Virginia Medical School, 700 West Olney Road, Norfolk, VA, USA. ${ }^{5}$ Leroy T. Canoles Jr. Cancer Research Center, Eastern Virginia Medical School, 700 West Olney Road, Norfolk, Virginia, USA.

\section{Authors' contributions}

PS conducted all functional and binding experiments, unless otherwise noted, and analyzed the results. CE conducted phagocytosis experiments and analyzed the results. RR contributed to the interpretation of results and editing of the manuscript. NK contributed to the interpretation of structural data and drafting or the manuscript. JN conducted the mass spectrometry experiments and analysis of these data. KC conceived of the study, coordinated design of the experiments, and drafted the manuscript with assistance as noted above. All authors read and approved the final manuscript.

\section{Competing interests}

The authors declare that they have no competing interests.

Received: 7 December 2011 Accepted: 5 March 2012

Published: 5 March 2012

\section{References}

1. Nicolau DP, Stein GE: Therapeutic options for diabetic foot infections: a review with an emphasis on tissue penetration characteristics. J Am Podiatr Med Assoc 2010, 100:52-63.

2. Lipsky BA, Pecoraro RE, Ahroni JH: Foot ulceration and infections in elderly diabetics. Clin Geriatr Med 1990, 6:747-769.

3. Lipsky BA, Pecoraro RE, Wheat $L$ : The diabetic foot. Soft tissue and bone infection. Infect Dis Clin North Am 1990, 4:409-432.

4. El-Gilany AH, Fathy $\mathrm{H}$ : Risk factors of recurrent furunculosis. Dermatol Online J 2009, 15:16.

5. Galkowska H, Podbielska A, Olszewski WL, Stelmach E, Luczak M, Rosinski G, Karnafel W: Epidemiology and prevalence of methicillin-resistant Staphylococcus aureus and Staphylococcus epidermidis in patients with diabetic foot ulcers: focus on the differences between species isolated from individuals with ischemic vs. neuropathic foot ulcers. Diabetes Res Clin Pract 2009, 84:187-193. 
6. Rogers BA, Drake AK, Spelman D: Methicillin resistant Staphylococcus aureus endocarditis in an Australian tertiary hospital: 1991-2006. Heart Lung Circ 2009, 18:208-213.

7. Andersen CA, Roukis TS: The diabetic foot. Surg Clin North Am 2007, 87:1149-1177.

8. Hartemann-Heurtier A, Senneville E: Diabetic foot osteomyelitis. Diabetes Metab 2008, 34:87-95.

9. Bader MS: Diabetic foot infection. Am Fam Physician 2008, 78:71-79.

10. Van den-Berghe $G$, Wouters $P$, Weekers F, Verwaest $C$, Bruyninckx F, Schetz M, Vlasselaers D, Ferdinande P, Lauwers P, Bouillon R: Intensive insulin therapy in the critically ill patients. N Engl J Med 2001, 345:1359-1367.

11. Bader MS: Hyperglycemia and mortality in elderly patients with Staphylococcus aureus bacteremia. South Med J 2007, 100:252-256.

12. Petry F, Loos M: Bacteria and Complement. In The human complement system in health and disease. Edited by: Volanakis JE, Frank MM. New York: Marcel Dekke; 1998:375-392.

13. Watts A, Ke D, Wang Q, Pillay A, Nicholson-Weller A, Lee JC: Staphylococcus aureus strains that express serotype 5 or serotype 8 capsular polysaccharides differ in virulence. Infect Immun 2005, 73:3502-3511.

14. Jongerius I, Kohl J, Pandey MK, Ruyken M, Van-Kessel KP, Van-Strijp JA, Rooijakkers SH: Staphylococcal complement evasion by various convertase-blocking molecules. J Exp Med 2007, 204:2461-2471.

15. Lambris JD, Ricklin D, Geisbrecht BV: Complement evasion by human pathogens. Nat Rev Microbiol 2008, 6:132-142.

16. Frank MM, Atkinson JP: Complement System. In Samter's Immunologic Disease. Edited by: Austen KF, Frank MM, Atkinson JP, Cantor H. New York: Lippincott Williams and Wilkins; 2001:281-298.

17. Joiner KA, Warren KA, Brown EJ, Swanson J, Frank MM: Studies on the mechanism of bacterial resistance to complement-mediated killing. IV. C5b-9 forms high molecular weight complexes with bacterial outer membrane constituents on serum-resistant but not on serum-sensitive Neisseria gonorrhoeae. J Immunol 1983, 131:1443-1451.

18. Yonemasu K, Kitajima H, Tanabe S, Ochi T, Shinkai H: Effect of age on C1q and C3 levels in human serum and their presence in colostrum. Immunology 1978, 35:523-530.

19. Turina M, Fry DE, Polk HC Jr: Acute hyperglycemia and the innate immune system: clinical, cellular, and molecular aspects. Crit Care Med 2005, 33:1624-1633.

20. Rich J, Lee JC: The pathogenesis of Staphylococcus aureus infection in the diabetic NOD mouse. Diabetes 2005, 54:2904-2910.

21. Maillet F, Petitou M, Choay J, Kazatchkine MD: Structure-function relationships in the inhibitory effect of heparin on complement activation: independency of the anti-coagulant and anti-complementary sites on the heparin molecule. Mol Immunol 1988, 25:917-923.

22. Austin GE, Mullins RH, Morin LG: Non-enzymic glycation of individual plasma proteins in normoglycemic and hyperglycemic patients. Clin Chem 1987, 33:2220-2224.

23. Hostetter MK: Handicaps to host defense. Effects of hyperglycemia on C3 and Candida albicans. Diabetes 1990, 39:271-275.

24. Mann J, O'Brien R, Hostetter MK, Alper CA, Rosen FS, Babior BM: The third component of complement: covalent attachment of a radioactive sugar to the labile binding site of C3 via the alternative pathway. J Immunol 1981, 126:2370-2372.

25. Law SK, Minich TM, Levine RP: Binding reaction between the third human complement protein and small molecules. Biochemistry 1981, 20:7457-7463.

26. Mastropaolo MD, Evans NP, Byrnes MK, Stevens AM, Robertson JL, Melville SB: Synergy in polymicrobial infections in a mouse model of type 2 diabetes. Infect Immun 2005, 73:6055-6063.

27. Deitch EA: Opsonic activity of blister fluid from burn patients. Infect Immun 1983, 41:1184-1189.

28. Chao CY, Cheing GL: Microvascular dysfunction in diabetic foot disease and ulceration. Diabetes Metab Res Rev 2009, 25:604-614

29. Lambris JD, Sahu A, Wetsel RA: The chemistry and biology of C3, C4, and C5. In The human complement system in health and disease. Edited by: Volanakis JE, Frank MM. New York: Marcel Dekker; 1998:83-118.

30. Simonsen L, Holstein P, Larsen K, Bulow J: Glucose metabolism in chronic diabetic foot ulcers measured in vivo using microdialysis. Clin Physiol 1998, 18:355-359.
31. Cunnion KM, Lee JC, Frank MM: Capsule production and growth phase influence binding of complement to Staphylococcus aureus. Infect Immun 2001, 69:6796-6803.

32. Mazmanian SK, Ton-That H, Schneewind O: Sortase-catalysed anchoring of surface proteins to the cell wall of Staphylococcus aureus. Mol Microbiol 2001, 40:1049-1057.

33. Hair PS, Echague CG, Sholl AM, Watkins JA, Geoghegan JA, Foster TJ, Cunnion KM: Clumping factor A interaction with complement factor I increases C3b cleavage on the bacterial surface of Staphylococcus aureus and decreases complement-mediated phagocytosis. Infect Immun 2010, 78:1717-1727.

34. Custer JW: Blood Chemistries and Body Fluids. In The Harriet Lane Handbook. 18 edition. Edited by: Custer W, Rau RE. Philadelphia: Mosby Elsevier; 2009:667-688.

35. Zehtabchi S, Sinert R, Wallace D, Caton M, Chen J, Chang B, Lucchesi M: Is routine electrolyte testing necessary for diabetic patients who present to the emergency department with moderate hyperglycemia? Eur J Emerg Med 2007, 14:82-86.

36. Cunnion KM, Hair PS, Buescher ES: Cleavage of complement C3b to iC3b on the surface of Staphylococcus aureus is mediated by serum complement factor I. Infect Immun 2004, 72:2858-2863.

37. Fowler VG Jr, Scheld WM, Bayer AS: Endocarditis and intravascular infections. In Mandell, Douglas, and Bennett's Principles and Practice of Infectious Diseases. Volume 1067.. 7 edition. Edited by: Mandell GL, Douglas JE, Dolin R. Philadelphia: Churchill Livingstone; 1067-1112.

38. Cunnion KM, Zhang HM, Frank MM: Availability of complement bound to Staphylococcus aureus to interact with membrane complement receptors influences efficiency of phagocytosis. Infect Immun 2003, 71:656-662.

39. Cunnion KM, Buescher ES, Hair PS: Serum complement factor I decreases Staphylococcus aureus phagocytosis. J Lab Clin Med 2005, 146:279-286.

40. Guo X, Ward MD, Tiedebohl JB, Oden YM, Nyalwidhe JO, Semmes OJ: Interdependent phosphorylation within the kinase domain T-loop Regulates CHK2 activity. J Biol Chem 2010, 285:33348-33357.

41. Liu H, Sadygov RG, Yates JR: A model for random sampling and estimation of relative protein abundance in shotgun proteomics. Anal Chem 2004, 76:4193-4201.

42. Zybailov B, Coleman MK, Florens L, Washburn MP: Correlation of relative abundance ratios derived from peptide ion chromatograms and spectrum counting for quantitative proteomic analysis using stable isotope labeling. Anal Chem 2005, 77:6218-6224.

43. Old WM, Meyer-Arendt K, Aveline-Wolf L, Pierce KG, Mendoza A, Sevinsky JR, Resing KA, Ahn NG: Comparison of label-free methods for quantifying human proteins by shotgun proteomics. Mol Cell Proteomics 2005, 4:1487-1502.

44. Zhu W, Smith JW, Huang CM: Mass spectrometry-based label-free quantitative proteomics. J Biomed Biotechnol 2010, 2010:840518.

45. Searle BC: Scaffold: a bioinformatic tool for validating MS/MS-based proteomic studies. Proteomics 2010, 10:1265-1269.

46. Janssen BJ, Huizinga EG, Raaijmakers HC, Roos A, Daha MR, NilssonEkDahl K, Nilsson B, Gros P: Structures of complement component C3 provide insights into the function and evolution of immunity. Nature 2005, 437:505-511.

47. Hair PS, Ward MD, Semmes OJ, Foster TJ, Cunnion KM: Staphylococcus aureus clumping factor $\mathrm{A}$ binds to complement regulator factor I and increases factor I cleavage of C3b. J Infect Dis 2008, 198:125-133.

48. Projan JS, Norvick RP: The molecular basis of pathogenicity. In The Staphylococci in human disease. Edited by: Crossley KB, Archer GL. New York: Churchill Livingstone; 1997:55-81.

49. Nilsson B, Nilsson UR: SDS denaturation of complement factor C3 as a model for allosteric modifications occurring during $\mathrm{C} 3 \mathrm{~b}$ binding: demonstration of a profound conformational change by means of circular dichroism and quantitative immunoprecipitation. Immunol Lett 1986, 13:11-14.

50. Hugli TE, Morgan WT, Muller-Eberhard HJ: Circular dichroism of C3a anaphylatoxin. Effects of $\mathrm{pH}$, heat, guanidinium chloride, and mercaptoethanol on conformation and function. J Biol Chem 1975, 250:1479-1483

51. Manavalan P, Johnson CW Jr: Sensitivity of circular dichroism to protein tertiary structure class. Nature 1983, 305:831-832. 
52. McManus LM, Bloodworth RC, Prihoda TJ, Blodgett UL, Pinckard RN: Agonist-dependent failure of neutrophil function in diabetes correlates with extent of hyperglycemia. J Leukoc Biol 2001, 70:395-404.

53. Perner A, Nielsen SE, Rask-Madsen J: High glucose impairs superoxide production from isolated blood neutrophils. Intensive Care Med 2003, 29:642-645.

54. Ellahham S: Insulin therapy in critically ill patients. Vasc Health Risk Manag 2010, 6:1089-1101.

55. Stoeckle M, Kaech C, Trampuz A, Zimmerli W: The role of diabetes mellitus in patients with bloodstream infections. Swiss Med Wkly 2008, 138:512-519.

56. Ilyas R, Wallis R, Soilleux EJ, Townsend P, Zehnder D, Tan BK, Sim RB, Lehnert H, Randeva HS, Mitchell DA: High glucose disrupts oligosaccharide recognition function via competitive inhibition: a potential mechanism for immune dysregulation in diabetes mellitus. Immunobiology 2011, 216:126-131.

57. Hostetter MK, Lorenz JS, Preus L, Kendrick KE: The iC3b receptor on Candida albicans: subcellular localization and modulation of receptor expression by glucose. J Infect Dis 1990, 161:761-768.

doi:10.1186/1479-5876-10-35

Cite this article as: Hair et al:: Hyperglycemic conditions inhibit C3mediated immunologic control of Staphylococcus aureus. Journal of Translational Medicine 2012 10:35.

\section{Submit your next manuscript to BioMed Central} and take full advantage of:

- Convenient online submission

- Thorough peer review

- No space constraints or color figure charges

- Immediate publication on acceptance

- Inclusion in PubMed, CAS, Scopus and Google Scholar

- Research which is freely available for redistribution

Submit your manuscript at www.biomedcentral.com/submit 